\title{
Péraldi Michel et Terrazzoni Liza, Mobilités et migrations européennes en (post) colonies
}

Jordan Pinel

\section{OpenEdition}

Édition électronique

URL : https://journals.openedition.org/remi/14016

DOI : 10.4000/remi.14016

ISSN : $1777-5418$

Éditeur

Université de Poitiers

\section{Édition imprimée}

Date de publication : 1 décembre 2019

Pagination : 306-307

ISBN : 979-10-90426-65-8

ISSN : 0765-0752

\section{Référence électronique}

Jordan Pinel, «Péraldi Michel et Terrazzoni Liza, Mobilités et migrations européennes en (post) colonies ", Revue européenne des migrations internationales [En ligne], vol. 35 - n³ et 4 | 2019, mis en ligne le 01 décembre 2019, consulté le 14 avril 2022. URL : http://journals.openedition.org/remi/14016 ; DOI : https://doi.org/10.4000/remi.14016

Ce document a été généré automatiquement le 14 avril 2022.

(c) Université de Poitiers 


\title{
Péraldi Michel et Terrazzoni Liza, Mobilités et migrations européennes en (post) colonies
}

\author{
Jordan Pinel
}

\section{RÉFÉRENCE}

Péraldi Michel et Terrazzoni Liza (Dirs.) (2016) Mobilités et migrations européennes en (post) colonies, Cahiers d'Études africaines, 221-222, Paris, éditions de l'EHESS, 446 p., ISBN : 978-2-7132-2526-0

1 «Ce double numéro des Cahiers d'Études Africaines a pour objet et ambition de décrire les modes de présence et les mobilités des Européens dans quelques pays d'Afrique subsaharienne et du Maghreb» (p. 9). Dès l'introduction, intitulée «Anthropologie des Européens en Afrique ", Michel Péraldi et Liza Terrazzoni explicitent la démarche anthropologique dans laquelle ils entendent s'inscrire. Il s'agit de faire part, sans a priori, de la diversité des expériences sociales de ces migrants, tout en l'ancrant dans un contexte postcolonial.

2 Ce dossier se place dans la droite lignée des recherches déjà entamées des deux coordinateurs, notamment autour des installations européennes au Maghreb, au sein du centre d'analyse et d'intervention sociologique de l'École des hautes études en sciences sociales. Ces recherches avaient d'ailleurs abouti à un colloque international «Des Nord(s) vers les Sud(s) : État de la recherche sur les mobilités » qui s'est tenu à Paris en mai 2015. Le dossier s'est donc constitué sur un sujet émergeant dans la recherche en sciences sociales et avec le parti pris de sortir des idées préconçues sur des migrations qui ne s'effectueraient qu'exclusivement des « Suds » vers les « Nords». Le dossier a alors été constitué à partir d'un appel à contributions et le nombre d'articles du dossier - quatorze - reflète bien l'attrait de ces questions dans les recherches actuelles en sciences sociales. Outre le fait de présenter la démarche 
générale et les différents articles constituant le dossier, l'article introductif permet de comprendre le cheminement intellectuel de Michel Péraldi et Liza Terrazzoni : «nous avons fini par nous convaincre de la nécessité d'un débat théorique sur le sens des mobilités, avant même leur inventaire, et d'un retour réflexif au silence des sciences sociales sur ces thèmes » (p. 11).

3 Les articles se concentrent sur la présence d'Européens dans plusieurs pays africains Algérie, Angola, Cameroun, Gabon, Ghana, Madagascar, Maroc, République Démocratique du Congo, Sénégal - et de manière plus large parfois en Afrique subsaharienne et Afrique de l'Ouest. Tous ont en commun d'être des anciennes colonies européennes qui continuent à accueillir, sous diverses formes, des migrants européens. La lecture du dossier amène au constat d'une continuité des migrations européennes : loin de l'interruption migratoire post-indépendance qu'on imagine, on est bien ici dans le cadre d'un continuum migratoire. L'un des avantages de ce dossier - surtout pour le lecteur français - est par ailleurs de compter parmi ces articles des analyses sur des États qui furent d'anciennes colonies non françaises (Angola, Ghana, RDC), permettant ainsi de décentrer le regard du cas français en privilégiant une échelle européenne, et de disposer d'analyses francophones là où les études anglophones ou lusophones pourraient arrêter certains lecteurs (seulement deux des quatorze articles sont rédigés en anglais).

4 Le dossier s'articule autour de quatre grands thèmes : les migrations d'actifs (première partie : « hétérotopie entrepreneuriale »), les rapports affectifs en migration (deuxième partie: "Mobilités de l'amour»), le milieu scolaire au prisme du postcolonial (troisième partie: "L'ombre de l'éducateur: institution scolaire et mission civilisatrice?») et enfin les migrants «nord-sud» au prisme du post-colonialisme (quatrième partie : «Rapport colonial : continuités et bifurcation »). Ces quatre blocs et les différents articles qui les composent font émerger une diversité de profils parmi les migrants européens en Afrique. Entrepreneurs, " aventuriers ", amoureuses en couple mixte, coopérants ou encore écoliers, font partie des « figures » analysées. La liste n'est pas exhaustive et la chronique bibliographique «Présence, mobilité et migration vers les Suds" d'Ève Bantman-Masum donne un panorama encore plus large de ces mobilités, incluant le champ des recherches sur les lifestyle migration, les mobilités résidentielles et touristiques et les migrations de retraite. Cette chronique confirme la sensation que le champ d'études sur les migrations des « Nords » vers les «Suds » est en plein essor, et riche de contributions pluridisciplinaires. D'ailleurs, bien que la majorité des auteurs du dossier soient anthropologues et/ou sociologues, tous ne viennent pas de ces deux disciplines. Quatre chercheurs viennent de l'histoire, des sciences politiques et des sciences de l'éducation, permettant d'apporter des concepts complémentaires à et propres à leur discipline. Le hasard des propositions de contributions étant ce qu'il est, les géographes figurent parmi les "absents notables » de ce dossier où le post-colonialisme est finalement assez peu observé au prisme de la spatialité. Des approches juridique ou littéraire auraient également été les bienvenues. Mais c'est là que nous pouvons nous reporter au colloque international « Des Nord(s) vers les Sud(s) : État de la recherche sur les mobilités » et aux travaux auxquels les auteurs nous renvoient au fil des chapitres.

5 L'un des principaux enseignements de ce numéro thématique est la forme individualiste de ce mouvement migratoire, qui contraste avec les formes qu'il a prises dans l'histoire coloniale au travers des missions coloniales civilisatrices notamment. Ce 
sont de "nouveaux migrants", comme le rappellent les coordinateurs dans leur chapitre introductif, car ils sont le produit des logiques d'autonomisation et d'individuation qui caractérisent nos sociétés actuelles. Le sujet idéologiquement et politiquement sensible du post-colonialisme est traité ici avec finesse. Le choix même des termes utilisés pour parler du phénomène - «migrations » vs. " expatriation » par exemple - montre qu'aucun mot n'est anodin et qu'au contraire, ils désignent souvent des rapports de domination. Les auteurs sortent des passions politiques pour renouveler la pensée postcoloniale en envisageant ces acteurs européens de la migration sous toutes leurs formes et non pas seulement comme des (néo)colons, des expatriés, des coopérants.

6 Ce dossier riche en études de cas diverses amène une volonté de comparaison à une plus grande échelle, dans des contextes culturels différents.

\section{AUTEURS}

JORDAN PINEL

Géographe, Doctorant, Migrinter/Université de Poitiers 